\title{
Wikipédia e museus: uma parceria possível?
}

\author{
¿Wikipedia y museos: una asociación posible?
}

Wikipedia and museums: a possible partnership?

\author{
Juliana Monteiro'
}

Palavras-chave:

Wikipédia

Museus

Acesso aberto

\section{Resumo:}

A Wikipédia é, hoje, considerada uma das principais fontes terciárias de informação da atualidade, tendo grande impacto na difusão de conteúdos relacionados a todas as áreas do conhecimento humano. Outro aspecto importante da Wikipédia é o modo como ela é gerenciada: por uma comunidade ativa de editores e editoras voluntários, que constroem ferramentas, regras e colaboram para melhorar ou criar artigos. Nesse sentido, muitos museus têm procurado trabalhar com a Wikipédia e seus projetos irmãos como parte de uma estratégia digital para disseminar o conhecimento que produzem. As possibilidades derivadas de tal conexão entre instituições culturais e Wikipédia são numerosas, desde a reutilização criativa de imagens e outros conteúdos digitais relacionados às coleções, até a produção de novos dados, com o apoio dos editores da enciclopédia, sobre a coleções. É, portanto, uma forma aberta, colaborativa e inovadora de criar novos contextos para o patrimônio cultural. Sendo assim, é válido discutir quais os impactos que parcerias entre museus e a Wikipédia podem ter para a forma como as instituições museológicas se portam diante do ciclo de produção de conhecimento. Esse é um dos objetivos do presente artigo. 


\begin{abstract}
Resumen:
Wikipedia es, hoy, considerada una de las principales fuentes terciarias de información de la actualidad, teniendo gran impacto en la difusión de contenidos relacionados a todas las áreas del conocimiento humano. Otro aspecto importante de Wikipedia es el modo en que es administrada: por una comunidad activa de editores y editores voluntarios, que construyen herramientas, reglas y colaboran para mejorar o crear artículos. En este sentido, muchos museos han intentado trabajar con Wikipedia y sus proyectos hermanos como parte de una estrategia digital para diseminar el conocimiento que producen. Las posibilidades derivadas de tal conexión entre instituciones culturales y Wikipedia son numerosas, desde la reutilización creativa de imágenes y otros contenidos digitales relacionados a las colecciones, hasta la producción de nuevos datos, con el apoyo de los editores de la enciclopedia, sobre las colecciones. Es, por lo tanto, una forma abierta, colaborativa e innovadora de crear nuevos contextos para el patrimonio cultural. Siendo así, es válido discutir cuáles son los impactos que las asociaciones entre museos y Wikipedia pueden tener para la forma en que las instituciones museológicas se portan ante el ciclo de producción de conocimiento. Este es uno de los objetivos del presente artículo.
\end{abstract}

\section{Palabras clave:}

Wikipedia

Museos

Acceso abierto

\section{Keywords:}

Wikipedia

Museums

Open Access

\section{Abstract:}

Wikipedia is today considered one of the main tertiary sources of information of the present time, having great impact in the diffusion of contents related to all the areas of human knowledge. Another important aspect of Wikipedia is how it is managed: by an active community of volunteer editors, who build tools, rules, and collaborate to improve or create articles. In this sense, many museums have sought to work with Wikipedia and its sister projects as part of a digital strategy to disseminate the knowledge they produce. The possibilities derived from such a connection between cultural institutions and Wikipedia are numerous, from the creative reuse of images and other digital contents related to the collections, to the production of new data, with the support of the editors of the encyclopedia, on the collections. It is, therefore, an open, collaborative and innovative way of creating new contexts for cultural heritage. Therefore, it is worth discussing the impact that partnerships between museums and Wikipedia can have on the way that museums participate in the cycle of knowledge production. This is one of the objectives of this article. 


\section{Wikipédia e museus: uma parceria possível?}

\section{Introdução}

O presente artigo tem dois objetivos. Primeiro, visa apresentar as principais potencialidades e desafios no uso da Wikipédia por museus, trazendo observações mais pontuais sobre seus projetos irmãos, a saber: Wikimedia Commons, Wikitada, Wikibooks, Wikicionário e outros. $\mathrm{E}$, em segundo lugar, quer discutir, ainda que de forma preliminar, em que medida tal utilização pode implicar em parcerias transformadoras para as partes envolvidas, principalmente para os museus.

Compreende-se que a Wikipédia e seus projetos irmãos se apresentam como vias possíveis para operacionalizar novas formas de compartilhamento de materiais relacionados às coleções museológicas, como fotos, vídeos, áudios, documentos escaneados entre outros. Logo, todas essas plataformas têm um forte potencial de maximizar o acesso às coleções, contribuindo também para aumentar, ainda que indiretamente, a presença digital de instituições museológicas.

Cumpre ressaltar por último que todas as reflexões apresentadas no presente artigo são frutos de minha participação em projetos que procuram unir instituições culturais e os projetos Wikimedia, em particular a Wikipédia. Assim, pode-se dizer que a metodologia para escrita do texto é empírica, usando como procedimento a sistematização de referenciais advindos da prática e sua análise à luz de conceitos da Museologia, da Ciência da Informação e de áreas afins.

\section{O que é a Wikipédia}

A Wikipédia é a maior enciclopédia online gratuita do mundo. Criada for- malmente em 2001 (WIKIPEDIA, 2018a), a plataforma estabeleceu uma nova maneira de criar e difundir o conhecimento, atingindo uma escala de mais de 5 bilhões de artigos em sua versão em inglês (WIKIPEDIA, 2018b) e pouco mais de 1 milhão de artigos em sua versão em português (WIKIPÉDIA, 2018c).

A Wikipédia possui regras específicas de edição, que devem ser respeitadas por qualquer um interessado em colaborar. Um dos seus pilares é que a Wikipédia é uma enciclopédia, logo, uma fonte terciária de informação e não o local para publicação de dados ou pesquisas inéditas. Outro ponto relevante a ser destacado é que tudo o que nela consta, teoricamente, deve possuir relevância enciclopédica. Em outras palavras, a Wikipédia pode ser uma plataforma para todas as facetas do conhecimento humano, o que não significa que todo o conhecimento deverá ser registrado ali.

Além da Wikipédia, há seus projetos irmãos, como Wikidata, Wikimedia Commons, Wikicionary, Wikibooks, Wikiquote etc". Todos eles são conhecidos genericamente como projetos Wikimedia e possuem regras próprias de contribuição, que podem ser iguais ou não às da Wikipédia - o maior e mais visado projeto Wikimedia de todos. Vale ressaltar também que não é estranho encontrar voluntários ou voluntárias que se dedicam exclusivamente a somente um ou dois dos projetos, sendo raras as pessoas que atuam em muitas ou todas as frentes ao mesmo tempo.

Todos os projetos são atualmente mantidos por meio da Wikimedia Foundation, organização sem fins lucrativos sediada nos Estados Unidos. A Fundação tem o papel de fazer advocay e angariar recursos para cada um dos projetos, bem como estimular o engajamento de voluntários e voluntárias. É a Fundação também que organiza ou ajuda a organizar eventos locais ou globais voltados à integração 
entre pessoas que atuam, em diferentes instâncias, nos projetos Wikimedia.

Todo esse universo de iniciativas compartilha do mesmo objetivo comum: a de que o conhecimento humano deve ser livre e que qualquer pessoa pode colaborar com a ampliação do acesso a ele. A colaboração pode se dar de diferentes formas, sendo possível citar algumas: criação ou melhoria de artigos na Wikipédia, carregamento de arquivos multimídia já em domínio público ou com licenciamento aberto no Wikimedia Commons, ou mesmo a estruturação de conjuntos de dados no Wikidata.

Além de milhares de indivíduos que são colaboradores ativos das comunidades wiki de cada projeto, também existem instituições GLAM (acrônimo em inglês para galerias, bibliotecas, arquivos e museus) que se tornaram parte desse universo. Uma das várias razões para tal fenômeno é que as instituições culturais estão tentando envolver-se com os projetos Wikimedia como uma forma de diversificar e ampliar os (re)usos de seus conteúdos digitais relacionados às coleções, como imagens e dados (FLETCHER et al., 2014). Nesse sentido, cada vez mais é comum verificar a realização de parcerias que visam congregar projetos Wikimedia, seus editores e editoras e instituições culturais. Tais iniciativas casadas são conhecidas como projetos GLAM Wiki.

No Brasil, as iniciativas GLAM Wiki não são novas. Porém, foi apenas em 2015-2016 que aconteceu a primeira experiência conhecida de um museu sediando um projeto GLAM Wiki, a saber, o projeto-piloto realizado pelo Museu da Imigração de São Paulo. Para execução da proposta, o museu contou com a colaboração direta do grupo Wiki Educação Brasil, composto de editores e editoras voluntários e experientes (MONTEIRO, 2016). Atualmente, o país já conta com uma série de projetos GLAM Wiki em andamento, concentradas especialmente nas cidades de São Paulo e Rio de Janeiro (WIKIPEDIAd, 2018).

Sendo assim, podemos nos perguntar quais as convergências e divergências existentes entre a Wikipédia e os museus, para explorar, a partir daí as possibilidades de parceria. E esse será o foco dos tópicos a seguir.

\section{Wikipédia e museus: convergências e divergências}

A partir da breve explicação apresentada anteriormente sobre como a Wikipédia funciona, é possível compreender que qualquer pessoa interessada pode se tornar uma editora e ajudar a enciclopédia a crescer. Porém, essa contribuição é regulada. Ou seja, longe estamos da ideia de que qualquer um faz o que quer na Wikipédia. Outro ponto importante também apresentado é que o conhecimento registrado na Wikipédia deve vir de fontes secundárias ou terciárias confiáveis, exigindo um trabalho de pesquisa contínuo e colaborativo.

É possível entender que o trabalho realizado pela Wikipédia e pelos museus compartilha algumas características em comum: ambos podem ser entendidos como hubs de comunidades "dedicadas à expansão do conhecimento" (TUNSCH, 2007). Mesmo o "público-alvo" da Wikipédia e dos museus é muito semelhante, se não igual: ambos destinam-se a um público vasto e variado, incluindo leigos e especialistas. No entanto, também podemos dizer que museus e a Wikipédia são diferentes em seus métodos de produção e verificação de conhecimento e suas formas de fornecer acesso à informação.

A enciclopédia on-line tem uma maneira dinâmica de criar e revisar seu conteúdo. Para criar um artigo na Wikipedia e mantê-lo lá, um editor ou editora deve fornecer fontes confiáveis para aquilo que está 
escrevendo e respeitar as regras gerais. A pessoa também não precisa ser especialista para iniciar um artigo sobre um assunto ou para contribuir com outro de seu interesse. Caso contrário, eles podem ser excluídos pela própria comunidade de editoras e editores da Wikipédia por falta de notoriedade.

O processo de construção e melhoria dos artigos tende a ser rápido e direto. Se houver alguma dúvida sobre referências ou mesmo sobre informações colocadas no corpo do texto, é possível discutir diretamente com outros editores e editoras e tentar encontrar um consenso sobre o que é melhor para o artigo. Tal postura dialógica é extremamente importante para o desenvolvimento saudável da Wikipédia, a fim de se evitar a qualquer custo as polêmicas "guerras de edição"III.

A Wikipédia também é bastante dinâmica no que se refere à facilidade e transparência no rastreamento do processo de elaboração e melhoria de um artigo. A criação e todas as edições seguintes feitas em um artigo, como correção ortográfica, inserção de fontes e imagens ou complemento de dados, ficam registradas e podem ser vistas por qualquer pessoa. Isso também contribui para que versões anteriores sejam comparadas entre si ou com a atual.

Os museus, por sua vez, podem produzir ou revisar conhecimento de diferentes formas, incluindo por meio de pesquisa inédita. Podem também realizar investigações que priorizem a interpretação de peças individuais ou de coleções inteiras. Por exemplo, um museu de arte talvez tenha a chance de verificar informações sobre seus objetos durante o processo de realização de uma exposição. Já no caso de um museu de história natural, ele pode ser dependente do avanço das ciências que lhes são relacionadas para mapear quais informações sobre suas coleções podem estar erradas.
Esses processos nem sempre são muito dinâmicos, já que acontecem em um ritmo particular. Isso significa que uma informação pode permenecer equivocada por algum tempo, até que seja possível alguém localizá-la ou corrigi-la. Além disso, não é qualquer pessoa que pode fazê-lo, mas apenas especialistas autorizados - geralmente curadores, documentalistas mais experientes ou mesmo profissionais com mais tempo de casa e maior conhecimento do acervo.

Os museus também possuem um ritmo próprio de disponibilização das informações que produzem. O público possui diferentes formas para entrar em contato com tais informações, seja por meio de seminários, palestras, exposições, ações educativas e outros eventos. Também há os produtos, como folders, catálogos impressos e on-line e materiais educativos, que podem servir como referências. Assim, os museus conseguem contribuir para o conhecimento humano, mas de uma forma particularizada e muito vezes vinculada ao ciclo de sua programação cultural.

Mas, se a Wikipédia e os museus por um lado são tão semelhantes e, por outro, totalmente diferentes, é possível imaginar que há espaço para diálogo entre eles? Estariam Wikipédia e museus em pé de igualdade em termos de autoridade na produção e revisão de conhecimento sobre o patrimônio cultural, por exemplo? Ou seriam eles complementares dentro do espectro de produção, organização e circulação de conhecimento?

Longe de oferecer respostas definitivas sobre a questão, é possível dizer que sim, existe espaço para diálogo entre museus e a Wikipédia. E é sobre isso que falaremos a seguir.

\section{Mudança necessária de paradigma}

É importante enfatizar que, para a parceria entre a Wikipédia e os museus fun- 
cionar, é necessária uma mudança de atitude - principalmente por parte das instituições e suas equipes. Durante muito tempo, os museus e seus profissionais, basearam-se em tradições de trabalho profundamente enraizadas na ideia do especialista que "sabe tudo". Ou seja, o profissional do museu como o especialista que detém o (único) conhecimento "correto" sobre os temas ou coleções de uma instituição.

Com isso, os museus ganharam uma imagem pública reconhecida como sendo lugares de autoridade absoluta sobre campos específicos do conhecimento. Tem havido muita discussão e debate sobre a importância de os museus lutarem contra essa imagem, uma vez que muitas vezes ela causa mais distância entre o museu e a sociedade do que ajuda a construir pontes entre eles. No entanto, se os museus - e, por consequência, seus profissionais - realmente quiserem mudar essa percepção, eles precisam reavaliar o modo como constroem e compartilham sua produção de conhecimento sobre as coleções.

E, acima de tudo, precisam deixar o lado o medo de perder o controle sobre a qualidade das informações ou sobre o "seu" acervo. No mundo em que vivemos, a ideia de controle absoluto no ambiente web é sempre relativa e frágil. $E$ a concepção de que um acervo, parcela de um patrimônio cultural, é de "alguém" que não a própria sociedade, também é algo controverso, para dizer o mínimo.

Uma ilustração clara do quanto não vale a pena manter tal postura são os inúmeros casos em que instituições acabam por ver partes de seu acervo que já estão em domínio público, por exemplo, sendo compartilhadas livremente na internet - causando o que hoje é conhecido como "Yellow Milkmaid Syndrome" (algo como "Síndrome da Leiteira", em uma tradução livre $)^{\mathrm{IV}}$. Um detalhe importante de tal situação é de que, na maioria dos casos, as imagens podem até conter a atribuição correta de autoria, mas não indicam em absoluto onde esses itens estão - e lá se vai uma chance rara da instituição de ser mais (re)conhecida pelo seu trabalho. Ou seja, o medo, ainda que legítimo em alguns aspectos, pode levar a um isolacionismo, fazendo a instituição perder o "bonde da história".

Cumpre ressaltar que não se trata aqui de defender que qualquer coisa seja livremente compartilhada a qualquer custo na Wikipédia ou em algum de seus projetos irmãos pelos museus. Ou mesmo que uma instituição museológica abra mão de sua expertise. Porém, significa dizer que abrir uma coleção para o "mundo", incluindo a Wikipédia e projetos correlatos, torna a instituição um agente ativo de mudança de paradigmas na forma como até hoje se dá a relação museu-sociedade.

Portanto, começar um projeto com a Wikipédia (ou com outro projeto Wikimedia) não é só iniciar uma jornada focada no seu uso puro e simples. É, sobretudo, começar uma jornada que implica na admissão de outras vozes no processo de construção de conhecimento sobre os acervos, titulares das coleções e até sobre a própria história da instituição.

É admitir, também, que pensar em questões de acesso ao acervo é algo que deve fazer parte do cotidiano dos profissionais do museu, preferencialmente em uma base contínua e sistemática. Nós, enquanto trabalhadores e trabalhadoras de museus, não podemos mais considerar a disponibilização como algo "além" daquilo que fazemos no dia a dia. Ao contrário, devemos sempre considerar o acesso público aos conteúdos relacionados ao acervo, sempre que ele for possível, em algo que é tão corriqueiro e vital quanto catalogar, higienizar ou expor um objeto da coleção.

É possível entender que a Wikipédia e os museus podem ser partes corres- 
pondentes do processo de criação ou revisão de informações sobre o patrimônio cultural. Os museus podem continuar sendo o local para a realização e publicação de pesquisas mais aprofundadas e detaIhadas, e a Wikipédia pode ser um dos lugares para tornar isso mais acessível sempre lembrando que a enciclopédia não é o lugar para pesquisas inéditas.

Alternativamente, a Wikipédia pode ser o lugar onde um museu pode procurar outras fontes de informação sobre suas coleções, buscando nas referências de cada bom artigo novas possibilidades de enriquecer seus registros com novos dados. A Wikipédia também pode ser o lugar para um museu procurar novos públicos interessados em construir, de forma coletiva e voluntária, novos conteúdos sobre os acervos.

\section{Pensando a parceria na prática}

Considerando que museus e a Wikipédia podem, de fato, serem parceiros de sucesso, cumpre agora pensar no como fazer isso acontecer. Em todas as vezes que participei, direta ou indiretamente, de projetos GLAM Wiki, a forma de estruturar a colaboração era uma preocupação. E algo que aprendi durante tais experiências é que toda colaboração de um museu é uma colaboração válida. Em termos práticos, isso quer dizer que nem toda instituição museológica vai contribuir da mesma forma com a Wikipédia, mas que, independente da escala, tal contribuição já será muito importante.

É interessante salientar tal entendimento para desconstruir uma idéia que, por vezes, volta e meia encanta e assombra as instituições brasileiras: a de que é necessário fazer algo de grande impacto para valer a pena o esforço. Se por um lado é inegável o apelo midiático de um anúncio de liberação em lote de centenas ou milhares de imagens em domínio público relacionadas ao acervo, por outro temos que lembrar que nem todos os museus possuem pernas ou braços para algo dessa envergadura.

Alguns exemplos de sucesso muito citados e que contribuem para a manutenção de tal ideia são o do Metropolitan Museum, dos Estados Unidos, que desde 2017 passou a disponibilizar imagens em domínio público de suas obras em alta resolução, atingindo a marca atual de mais 406.000 fotos (METROPOLITAN, s/d). Outro exemplo famoso é o do Rijksmuseum, na Holanda, que hoje já acumula a impressionante marca de 652.671 imagens em alta resolução e em domínio público (RIJKSMUSEUM, s/d) disponibilizadas desde 2011 (OPENGLAM, 2013).

Em ambos os casos, os museus liberam as imagens em seus websites, em conjunto com uma política de acesso aberto, que indica claramente o que as pessoas podem ou não fazer com o material. O reaproveitamento das imagens para ilustrar artigos na Wikipédia ou para complementar o Wikimedia Commons é algo que acaba acontecendo naturalmente. Os editores e editoras fazem download dos arquivos a partir dos sites e os carregam posteriormente nos projetos Wikimedia. No caso do Metropolitan, logo após seu primeiro grande lote de imagens ser liberado em 2017, houve um ciclo de atividades focado no incentivo da reutilização das imagens em projetos Wikimedia (WIKIPÉDIAe, 2018).

Tais casos são, de fato, muito importantes de serem referenciados como possibilidades de atuação para instituições museológicas. Mas, vale reforçar que não são as únicas alternativas. Considerando nosso cenário brasileiro, ainda tímido nesse tipo de integração de museus com a Wikipédia, uma contribuição pequena, mas de qualidade, pode ser um grande incentivo para a continuidade da iniciativa de abertura e até de sua ampliação futura. Nesse caso, se estamos pensando em incorporação de uma cultura de acesso aberto ao cotidiano das instituições museológicas, com parti- 
cipação ativa de seus funcionários, talvez menos possa ser mais.

Nesse sentido, apresento o quadro abaixo a título de exemplo de possibilidades de parceria dos museus com a Wikipédia e seus projetos irmãos. Tal quadro foi elaborado com a finalidade de ajudar profissionais de museus e outras instituições culturais com quem trabalhei nos últimos anos a entender, de forma mais tangível, como poderiam colaborar. Não é uma sistematização final de todas as possibilidades, mas um ponto de partida para estimular algumas ideias e iniciar uma discussão mais estruturada em torno delas.

\begin{tabular}{|c|c|c|}
\hline Atividade & $\begin{array}{l}\text { Implica em produção de } \\
\text { conteúdo novo ou em } \\
\text { mobilização da equipe } \\
\text { da ORGANIZAÇÃO? }\end{array}$ & $\begin{array}{l}\text { Implica em edição da } \\
\text { equipe da ORGANIZAÇÃo } \\
\text { nos projetos Wikimedia? }\end{array}$ \\
\hline $\begin{array}{l}\text { Participação em campanhas } \\
\text { anuais focadas na melhoria da } \\
\text { Wikipédia, como a } 1 \mathrm{Lib}+1 \mathrm{Ref}^{\vee}\end{array}$ & $\begin{array}{l}\text { Sim, produção de listas } \\
\text { de referências } \\
\text { bibliográficas para } \\
\text { compartilhamento }\end{array}$ & $\begin{array}{l}\text { Sim. Exige esforço concentrado da } \\
\text { equipe. O trabalho de edição pode } \\
\text { ser feito por algumas pessoas da } \\
\text { equipe que aceitem ser editoras }\end{array}$ \\
\hline $\begin{array}{l}\text { Produção de textos que podem } \\
\text { ser usados para melhorar ou criar } \\
\text { artigos na Wikipédia em português } \\
\text { e em outras línguas }\end{array}$ & $\begin{array}{l}\text { Sim, a produção de } \\
\text { textos em si e sua } \\
\text { inserção posterior na } \\
\text { Wikipédia }\end{array}$ & $\begin{array}{l}\text { Sim. Exige esforço contínuo e de } \\
\text { longo prazo. Pode ser concentrado } \\
\text { em algumas pessoas da equipe } \\
\text { que aceitem ser editoras. Atenção } \\
\text { ao potencial conflito de interesses é } \\
\text { necessária }\end{array}$ \\
\hline $\begin{array}{l}\text { Carregamento de imagens do } \\
\text { acervo no Wikimedia Commons }\end{array}$ & $\begin{array}{l}\text { Sim, o carregamento em } \\
\text { si das imagens com seus } \\
\text { dados estruturados }\end{array}$ & $\begin{array}{l}\text { Sim. Exige esforço contínuo e de } \\
\text { longo prazo. Pode ser concentrado } \\
\text { em algumas pessoas da equipe } \\
\text { que aceitem ser editoras }\end{array}$ \\
\hline $\begin{array}{l}\text { Produção de dados como URIs ou } \\
\text { URLs, metadados sobre imagens } \\
\text { ou sobre titulares de coleções que } \\
\text { possam ser de interesse para os } \\
\text { projetos (como Wikidata ou } \\
\text { Wikimedia Commons) }\end{array}$ & $\begin{array}{l}\text { Sim, a criação e } \\
\text { organização de dados } \\
\text { estruturados em si }\end{array}$ & $\begin{array}{l}\text { Não necessariamente, pois a } \\
\text { ORGANIZAÇÃO pode organizar os } \\
\text { dados e disponibilizá-los em site } \\
\text { próprio, por exemplo. Os } \\
\text { voluntários e voluntárias que atuam } \\
\text { na Wikipédia e outros projetos } \\
\text { podem usá-los a partir disso }\end{array}$ \\
\hline $\begin{array}{l}\text { Organização de listas de } \\
\text { referências bibliográficas sobre } \\
\text { temas/tópicos de interesse da } \\
\text { ORGANIZAÇÃO e que estejam } \\
\text { contemplados na Wikipédia ou em } \\
\text { outros projetos Wikimedia }\end{array}$ & $\begin{array}{l}\text { Sim, produção em si de } \\
\text { listas de referências } \\
\text { bibliográficas }\end{array}$ & $\begin{array}{l}\text { Não necessariamente, pois a } \\
\text { ORGANIZAÇÃO pode deixar que } \\
\text { o trabalho de edição aconteça } \\
\text { pelas mãos da comunidade de } \\
\text { voluntários e voluntárias durante } \\
\text { realização de maratonas de } \\
\text { edição, os edit-a-thons }\end{array}$ \\
\hline $\begin{array}{l}\text { Participação em campanhas } \\
\text { anuais focadas em temas } \\
\text { específicos, como a } \\
\text { Art+Feminism }\end{array}$ & $\begin{array}{l}\text { Sim, a produção em si de } \\
\text { listas de nomes de } \\
\text { mulheres artistas que } \\
\text { sejam de interesse para a } \\
\text { ORGANIZAÇÃO destacar, } \\
\text { bem como listas de } \\
\text { referências bibliográficas }\end{array}$ & $\begin{array}{l}\text { Não necessariamente, pois a } \\
\text { ORGANIZAÇÃO pode deixar que } \\
\text { o trabalho de edição aconteça } \\
\text { pelas mãos da comunidade de } \\
\text { voluntários e voluntárias durante } \\
\text { realização de maratonas de } \\
\text { edição, os edit-a-thons }\end{array}$ \\
\hline
\end{tabular}




\begin{tabular}{|c|c|c|}
\hline Atividade & $\begin{array}{l}\text { Implica em produção de } \\
\text { conteúdo novo ou em } \\
\text { mobilização da equipe } \\
\text { da ORGANIZAÇÃO? }\end{array}$ & $\begin{array}{l}\text { Implica em edição da } \\
\text { equipe da ORGANIZAÇÃO } \\
\text { nos projetos Wikimedia? }\end{array}$ \\
\hline $\begin{array}{l}\text { Categorização de imagens no } \\
\text { Wikimedia Commons }\end{array}$ & $\begin{array}{l}\text { Sim, a categorização das } \\
\text { imagens em si }\end{array}$ & $\begin{array}{l}\text { Não necessariamente, pois a } \\
\text { equipe da ORGANIZAÇÃO pode } \\
\text { apenas indicar na página de } \\
\text { discussão da imagem as categorias } \\
\text { sugeridas. Exige maior grau de } \\
\text { conhecimento das ferramentas dos } \\
\text { projetos Wikimedia }\end{array}$ \\
\hline $\begin{array}{l}\text { Acompanhamento de artigos de } \\
\text { destaque que sejam de interesse } \\
\text { da ORGANIZAÇÃO, para } \\
\text { verificação periódica da eventual } \\
\text { necessidade de complementação } \\
\text { ou correção }\end{array}$ & $\begin{array}{l}\text { Sim, a leitura atenta dos } \\
\text { artigos }\end{array}$ & $\begin{array}{l}\text { Não necessariamente, pois a } \\
\text { ORGANIZAÇÃO pode deixar que } \\
\text { o trabalho de edição aconteça } \\
\text { pelas mãos da comunidade de } \\
\text { voluntários e voluntárias durante } \\
\text { realização de maratonas de } \\
\text { edição, os edit-a-thons }\end{array}$ \\
\hline $\begin{array}{l}\text { Realização de maratonas } \\
\text { presenciais ou online (edit-a-thons) } \\
\text { de edição sobre temas/tópicos de } \\
\text { interesse do Instituto, durante as } \\
\text { quais a organização pode oferecer } \\
\text { listas de referências bibliográficas } \\
\text { para os participantes. As maratonas } \\
\text { podem ter como mote as datas de } \\
\text { aniversário ou de morte de algum } \\
\text { titular ou mesmo efemérides } \\
\text { relacionadas aos acervos (como } \\
\text { Dia do Livro, Dia da Música etc) }\end{array}$ & $\begin{array}{l}\text { Sim, o trabalho de } \\
\text { produção de um evento, } \\
\text { ainda que de baixo custo }\end{array}$ & $\begin{array}{l}\text { Não necessariamente, pois a } \\
\text { ORGANIZAÇÃO pode deixar } \\
\text { que o trabalho de edição } \\
\text { aconteça pelas mãos da } \\
\text { comunidade de voluntários e } \\
\text { voluntárias durante a maratona }\end{array}$ \\
\hline $\begin{array}{l}\text { Verificação de qualidade de artigos } \\
\text { de titulares ou de temas/tópicos de } \\
\text { interesse da ORGANIZAÇÃO na } \\
\text { Wikipédia em português e em } \\
\text { outras línguas para identificação de } \\
\text { pontos de atenção (e futuro } \\
\text { trabalho de planejamento) }\end{array}$ & $\begin{array}{l}\text { Sim, a leitura atenta } \\
\text { dos artigos }\end{array}$ & Não \\
\hline $\begin{array}{l}\text { Verificação da existência e } \\
\text { qualidade de imagens e outros itens } \\
\text { do acervo da ORGANIZAÇÃO no } \\
\text { Wikimedia Commons para } \\
\text { identificação de pontos de atenção } \\
\text { (e futuro trabalho de planejamento) }\end{array}$ & $\begin{array}{l}\text { Sim, a leitura atenta } \\
\text { dos artigos }\end{array}$ & Não \\
\hline
\end{tabular}

Quadro 1 - Possibilidades de colaboração de museus com a Wikipédia e seus projetos irmãos Fonte: PRÓPRIA AUTORA, 2018 
A partir do quadro, é possível compreender alguns pontos de atenção importantes, ainda que preliminares.

Um deles é que a parceria de um museu com a Wikipédia vai implicar, necessariamente, em algum tipo de mobilização interna de membros da equipe para ser executada. No caso das mobilizações que levam à produção (e/ou adaptação) de conteúdos, ela pode ser dar em menor ou maior escala, indo de uma única lista organizada de referências bibliográficas até mesmo a edição de centenas de artigos na Wikipédia. Mas, novamente, não importa tanto a escala, mas sim a vontade e a continuidade da proposta - principalmente no início de uma parceria entre a instituição e a Wikipédia.

Aqui, cabe uma nota importante sobre o envolvimento dos funcionários e funcionárias de um museu nesse tipo de iniciativa: nem todos os membros de uma equipe vão querer ser editores ou editoras. Nem todas as pessoas se sentem confortáveis com tal papel, por inúmeros motivos, e é preciso respeitar a decisão de cada um. Porém, essas mesmas pessoas podem ser, por exemplo, fundamentais para a produção de listas de referências bibliográficas especializadas sobre um tema - o que é um recurso inestimável para a Wikipédia. Portanto, o trabalho dentro de uma parceria entre museus e Wikipédia e outros projetos pode ser dividido de acordo com a vocação de cada profissional.

Outro ponto importante relativo à participação de membros de equipes é a importância de se evitar os conflitos de interesse ${ }^{\mathrm{VII}}$ a todo custo - como a melhoria do verbete da instituição pelos próprios funcionários ou funcionárias da casa, o que configura auto-propaganda. Há exemplos, de instituições como a State Library of New South Wales (WI-
KIPÉDIAf, 2018) que criaram políticas de participação de seus funcionários, compatíveis com as regras de edição da Wikipédia. Tais documentos podem servir, hoje, como pontos de partida para as instituições brasileiras para esclarecer, perante a comunidade de voluntários e voluntárias dos projetos Wikimedia, como seus colaboradores irão editar.

Outro ponto que não está escrito em todas as linhas do quadro, mas que é inerente a ele, é a possibilidade de convidar os editores e editoras voluntários dos projetos Wikimedia para colaborar com o museu. Tal convite pode ocorrer a qualquer tempo e envolvendo, de modo geral, qualquer uma das possibilidades listas acima - e não só a que se relaciona com sediar um edit-a-thon.

A presença de pessoas com maior experiência nas ferramentas e regras de edição podem ser um divisor de águas em iniciativas de museus que querem atuar de forma mais próxima aos projetos Wikimedia. A depender do contexto, é possível que elas se tornem "Wikimedistas em residência"VIII, atuando de forma mais próxima da instituição.

Vale a ressalva de que o quadro parte do pressuposto de que, antes de qualquer coisa, o museu precisa saber quais parcelas do seu acervo podem ser alvo de uma ação coordenada de disponibilização. Tal compromisso implica em identificar quais itens da coleção podem ser liberados para reuso na internet, incluindo a Wikipédia.

Para tanto, é extremamente importante que os museus prestem atenção para que as representações digitais de tais itens - como imagens geradas a partir de processos de digitalização ou de registro fotográfico - também estejam livres de restrições. Caso contrário, podemos ter situações em que a obra em 
si não é mais protegida, mas sua representação digital sim. Tudo isso precisa ser previamente negociado em contrato com os responsáveis pela criação dos representantes digitais, principalmente no caso das imagens produzidas por fotógrafos ou fotógrafas.

\section{Considerações finais}

O diálogo entre museus e a Wikipédia representa uma nova oportunidade para a recontextualização de coleções. E também uma oportunidade para museus e seus profissionais quebrarem, cada vez mais, barreiras relacionadas à imagem pública da instituição como espaço reservado a especialistas ou para conhecedores.

Os projetos Wikimedia colaboram na criação de novos links de hipertexto para tal conteúdo, permitindo que eles sejam reeditados, remixados e colocados em novas lógicas interpretativas. Em outras palavras, é possível dizer que as parcerias podem viabilizar o compartilhamento de coleções culturais abertamente por meio de plataformas populares e conhecidas, como a Wikipedia. E os museus só podem desfrutar de todos os benefícios dessa abertura para o mundo.

Por fim, vale ressaltar que as parcerias entre museus e a Wikipédia, bem como seus projetos irmãos, são possíveis, e uma realidade em expansão. Configuram, portanto, uma clara oportunidade de as instituições mostrarem sua produção de conhecimento, mudarem sua postura na forma de agir e ainda colaborar para cumprimento de sua função social na era digital.

\section{Referências}

EUROPEANA. The Yellow Milkmaid Syndrome - paintings with identity problems. 7/1/2015. Disponível em: https://pro.europeana.eu/post/the-yellow-milkmaid-syndrome-paintings-with-identity-problems. Acesso em: 16/12/2018.

FLECTHER, Neil et al. How to work successfully with Wikipedia: a guide for galleries, libraries, archives and museums. Reino Unido: Wikimedia UK, 2014. Disponível em: https://commons.wikimedia. org/wiki/File:WMUK_GLAM_booklet_2014.pdf. Acesso em: 19/11/2017.

METROPOLITAN. Open Access Artworks. s/d. Disponível em: https://www.metmuseum.org/art/ collection. Acesso em: 16/12/2018.

MONTEIRO, Juliana. Creative Commons and Museu da Imigração: notes on a Brazilian experience. 19/7/2016. Disponível em: https:// creativecommons.org/2016/07/19/creative-commons-museu-da-imigracao-notes-brazilian-experience/. Acesso em: 19/11/2017.

OPENGLAM. Case Study: Rijksmuseum releases 111.000 high quality images to the public domain. 27/2/2013. Disponível em: https://openglam.org/2013/02/27/case-study-rijksmuseum-releases-111-000-high-quality-images-to-the-public-domain/. Acesso em: 16/12/2018.

RIJKSMUSEUM. Rijkstudio. s/d. Disponível em: https://www.rijksmuseum.nl/ en/rijksstudio? $\mathrm{ii}=0 \& \mathrm{p}=0$ \& from $=2018-12$ 16T21\%3A15\%3A26.0357362Z. Acesso em: $16 / 12 / 2018$.

TUNSCH, Thomas. Museum Documentation and Wikipedia.de: possibilities, opportunities and advantages for scholars and museums. In: Museums and the Web. San Francisco: Museums and the Web, 2007. Disponível em: https://www. museumsandtheweb.com/biblio/museum_documentation_and_wikipedia_de_possibilities_o. html. Acesso em: 2/7/2018.

WIKIPÉDIAa. História da Wikipédia (artigo). 19/8/2018 (última alteração). Disponível em: https://pt.wikipedia.org/wiki/Hist\%C3\%B3ria_da_ Wikip\%C3\%A9dia. Acesso em: 16/12/2018.

WIKIPÉDIAb. Main page (página). 24/11/2018 (última alteração). Disponível em: https:// en.wikipedia.org/wiki/Main_Page. Acesso em: 16/12/2018. 
WIKIPÉDIAc. Página principal (página). 12/12/2018 (última alteração). Disponível em: https://pt.wikipedia.org/wiki/ Wikip\%C3\%A9dia:P\%C3\%A1gina_principal. Acesso em: 16/12/2018.

WIKIPÉDIAd. GLAM/Projetos em português (página). 25/9/2018 (última alteração). Disponível em: https://pt.wikipedia.org/wiki/ Wikip\%C3\%A9dia:GLAM/Projetos_em_ portugu $\%$ C3\%AAs. Acesso em: 16/12/2018.

WIKIPÉDIAe. GLAM/Metropolitan Museum of Art (página). 21/7/2018 (última alteração). Disponível em: https://en.wikipedia.org/wiki/ Wikipedia:GLAM/Metropolitan_Museum_of_Art. Acesso em: 16/12/2018.

WIKIPÉDIAf. GLAM/State Library of New South Wales (página). 3/11/2018 (última alteração). Disponível em: https://en.wikipedia.org/wiki/ Wikipedia:GLAM/State_Library_of_New_South_Wales. Acesso em: 16/12/2018.

\section{Recebido em 17/12/2018 Aprovado em 24/01/2019}

I Juliana Monteiro, Museóloga pela Universidade Federal da Bahia, Mestra em Ciência da Informação pela Universidade de São Paulo Coordenadora do curso técnico em Arquivo/ETEC Parque da Juventude. São Paulo, Brasil. Contato: julianamonteiro47@gmail.com

Il Para a relação de todos os projetos Wikimedia, consultar: https://pt.wikipedia.org/wiki/Wikimedia. Acesso em 16/12/2018.

III Para uma explicação mais detalhada a respeito das "guerras de edição", ver: https:// pt.wikipedia.org/wiki/Wikip\%C3\%A9dia:Guerra_de_ edi\%C3\%A7\%C3\%B5es. Acesso em 16/12/2018.

IV O nome da síndrome foi cunhado originalmente por Sarah Stierch, em referência à pintura de Vermeer intitulada "A leiteira". Stierch criou um blog onde relata casos de pinturas em domínio público com problemas de identidade, por causa da vasta quantidade de imagens online com problemas de cor, tamanho, resolução etc. Em decorrência de tal cenário, muitas vezes torna-se impossível saber como é a obra original. A causa de tal situação, conforme apontado em blog da Europeana (EUROPEANA, 2015), muitas vezes é a ausência de uma imagem fidedigna produzida pela instituição que detém fisicamente a obra e liberada na internet para reuso.

V Para saber mais, ver: https://meta.wikimedia.org/ wiki/The_Wikipedia_Library/1Lib1Ref. Acesso em: $16 / 12 / 2018$.

VI Para saber mais, ver: www.artandfeminism.org. Acesso em 16/12/2018.

VII Para saber mais sobre conflitos de interesse, ver: https://pt.wikipedia.org/wiki/Wikip\%C3\%A9dia:Conflito_ de_interesse. Acesso em: 16/12/2018.

VIII Para saber mais, ver: https://pt.wikipedia.org/wiki/ Wikimedista_em_resid\%C3\%AAncia. Acesso em: 16/12/2018. 